\title{
Performance Evaluation of Fractional Order Pid and Sliding Mode Control with Optimization Tuning Access
}

\author{
Chong Chee Soon, Rozaimi Ghazali, Shin Horng Chong, Chai Mau Shern, Yahaya Md. Sam, \\ Ahmad Anas Yusof
}

\begin{abstract}
The statistical analyses in the past showing the important properties of the electrohydraulic actuator (EHA) system, especially in the growth of the world economy. Dealing with the existing drawback in the EHA system, various types of control schemes have been introduced in the past. In this paper, to produce a more insightful view of the performance and the capabilities of the controller, three different types of controllers have been designed and compared. The favourite controller in the industry field, which is the proportional-integral-derivative (PID) controller will be first introduced. Follow by the improved PID controller, named Fractional Order (FO-PID) controller will be designed. Then, the prominent robust controller in the control field, called sliding mode controller (SMC) will be established. Instead of obtaining the controller's parameters without any appropriate technique, the well-known tuning technique in computer science, named particle swarm optimization (PSO) will be utilized. Referring to the performances produced by these controllers, it can be concluded that the SMC is capable to generate most desired control performance that produced the highest accuracy with the smallest error in the analyses.
\end{abstract}

Index Terms: Electro-Hydraulic, Fractional Order PID, Sliding Mode Control, Particle Swarm Optimization.

\section{INTRODUCTION}

Widespread applications dealing with electro-hydraulic actuator (EHA) system have been found typically in transportation, aeronautical and industry sectors. It is reported in [1], the sales of the components in fluid power exceeded 17.7 billion dollars, and the sales of the systems which use fluid power components exceeded 226 billion dollars in 2008. In the analysis, the markets are approximately $22.2 \%$ belong to the construction industries, $21.2 \%$ belong to the agriculture industries, $15.7 \%$ belong to the manufacturing industries, $13.7 \%$ belong to the palm oil and rubber machinery, and $27.2 \%$ belong to the miscellaneous applications.

Nowadays, the use of fluid power in the construction fields have been increasingly employed in the heavy engineering industries. The growing of the fluid power technology has fulfilled the demand in the control of increased quantities of

mass with higher precision and acceleration through the lowest power consumption. The hydraulic servomechanism with the characteristic of high power-to-weight ratio became an ideal component, especially dealing with the requirement of high weight and precise motion with the limited working space. The application of EHA system simultaneously reducing the operator's effort while increasing their safety issues in the manipulation of the heavy construction equipment.

In the EHA system, high precision in a quick response with high weight is the crucial factor that leads to the miscellaneous controller design. The control strategy and modelling of the system model is a vital process in the implementation of advanced engineering technologies. Generally, the EHA system is intrinsically highly nonlinear, time-varying, and contain various uncertainties which lead to the difficulties in the development of the accurate dynamic model and the controller designs. The origin of the nonlinearities in the system actuation consists of friction behaviour, oil compressibility changes with the working temperature, variations in the trapped fluid volume due to the piston motion, backlash in the control valve, and fluid compressibility [2]. These problems simultaneously motivate academia and researchers to further examine and design a powerful controller that is able to overcome these problems before applied to the potential industrial applications.

As the proportional-integral-derivative (PID) controller, which is a famous controller that always applied in the industrial applications, many researchers have trying to investigated and modified this controller with the integration of various kind of methods, including the modification of the structure in this controller, for instance the gain-scheduling control, or the fractional order (FO-PID) controller that is proven to be more effective in its performance, compared with the conventional PID controller [3-6], which have been applied to the hydraulic system [7-9]. Researchers also attempt to combine this controller, the conventional PID controller with the computational optimization method [10-15], and also the FOPID with the computational optimization method $[16,17]$, applied to the EHA system.

Revised Manuscript Received on August 19, 2019.

Chong Chee Soon, Centre for Robotics and Industrial Automation, Universiti Teknikal Malaysia Melaka, Malaysia.

Rozaimi Ghazali, Centre for Robotics and Industrial Automation, Universiti Teknikal Malaysia Melaka, Malaysia.

Shin Horng Chong, Centre for Robotics and Industrial Automation, Universiti Teknikal Malaysia Melaka, Malaysia. 
Another famous robust nonlinear controller, which is the sliding mode controller (SMC) has been extensively applied in the control of various engineering applications [18-20], and also in the EHA system [21-24]. With the integration of the computational tuning method, including particle Swarm Optimization (PSO) [25, 26], Gravitational Search Algorithm (GSA) [27], Genetic Algorithm [28] the SMC is proven to outperform than the SMC with no proper tuning technique in the acquirement of the controller's gains.

Therefore, the objective of this paper is to assess these existing control approaches, which are PID, FOPID, and also SMC, that are tuned by using the PSO optimization method. The examination of these controllers and methods in the simulation environment will be applied to the hardware that is in the development process. The organizations of this paper are, the summary of the EHA's system modelling is first presented, followed by the brief explanation of the optimization method in Section 2. The explanation of the FOPID and the SMC controllers is carried out in Section 3 and Section 4 respectively. The examination of the controller performances is pictured Section 5, and finally the conclusion of the study in Section 6.

\section{COMMON STRUCTURE OF THE EHA SYSTEM}

As the modelling of the EHA system has been well developed in the past, therefore, the discussion of the detail mathematical model of the EHA system can be found in [29]. Generally, the common components consist of power unit, control unit, and the actuator with sensing unit as illustrated in Fig. 1.
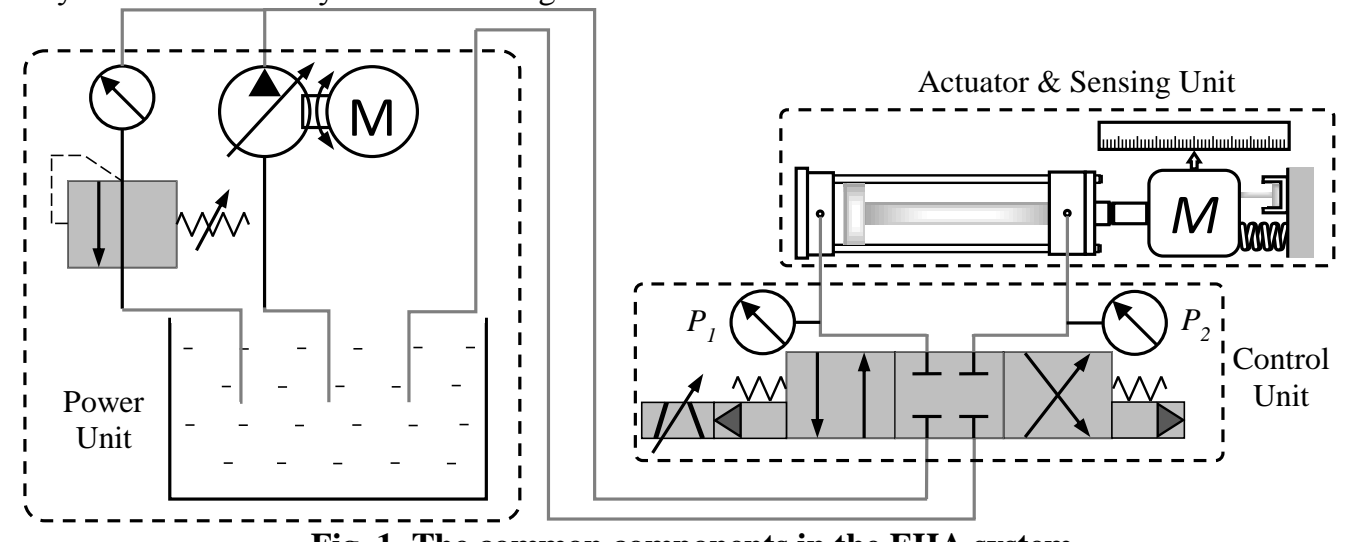

Fig. 1. The common components in the EHA system

Also, the discussion regarding the development of the PID controller and also the SMC are conducted in the previous paper [30], therefore, the purpose of this paper is to study the concept of the fractional order, implemented in the PID controller. Basically, this paper is developed according to the concept as depicted in the block diagram in Fig. 2.

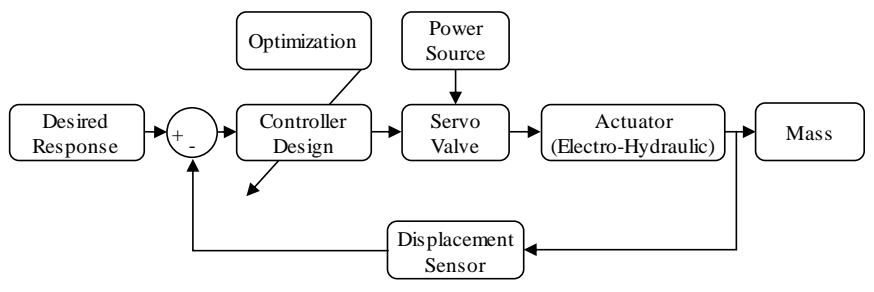

Fig. 2. The block diagram of the overall methodology

The EHA system is well-known to be intrinsically nonlinear. In order to improve its performance, especially when applied to the applications that required high precision factor, for example, aircraft and vehicle part pressing industry, different controllers emerge in the past. Hence, this study intends to design three different controllers, including PID, FOPID and SMC controllers to improve or to overcome the existing drawback in the EHA system.

The parameters of each controller are tuned by using the PSO tuning method, where the discussion regarding the PSO tuning method has been conducted in [30], with the equal parameters including the particle's size (50), the number of iterations (30), the acceleration (2 for both $c_{1}$ and $c_{2}$ ), the inertia weight (linearly decreased from 0.9 to 0.4 ) and most importantly the performance index, which is the Integral Time Absolute Error (ITAE) that use to obtain the minimum error. The obtained parameters will be applied to the designed controllers, and the performance of each controller will be evaluated.

\section{Fractional ORder PID Controller}

Fractional Order calculus involved in the control and the dynamic system was first proposed by Igor Podlubny in the 20th century [4]. By extending the general differential equations into the fractional order differential equations [31], the flexibilities of the fractional order calculus have been employed to the PID controller which yield the Fractional Order (FO-PID) controller.

Instead of the conventional PID controller, which is well-known in the control system that contains three parameters, two additional parameters which are the integrating order, $\lambda$ and the derivative order, $\mu$ have been integrated into the integral and derivative gains of the PID controller [31-33]. Commonly, the transfer function of the conventional PID controller is obtained by

$G(s)=\frac{U(s)}{E(s)}=K_{p}\left(1+\frac{1}{T_{i} s}+T_{d} s\right)$

Published By:
Blue Eyes Intelligence Engineering \& Sciences Publication 
where $K_{p}$ is the proportional gain, $T_{i}$ is the Integral gain time in constant time, and $T_{d}$ is the derivative gain in constant time. While the additional order that integrated to the FO-PID controller yields the transfer function of

$G(s)=\frac{U(s)}{E(s)}=K_{p}\left(1+\frac{1}{T_{i} s^{\lambda}}+T_{d} s^{\mu}\right)$

where the order $\lambda$ and $\mu$ are not necessarily the integer number [31]. If the order $\lambda$ and $\mu$ are assumed to be 1 , the convention PID controller is formed.

The common system with fractional order or known as a non-integer type of system can be found in the transmission line or the heat flow system. The closed-loop control system generally consists of integer or fractional order system with integer or fractional order controller, or the interchangeable of these system and control structure [34].

It is proven in the previous study, the FO-PID controller, or known as $\mathrm{PI}^{\lambda} \mathrm{D}^{\mu}$ controller is able to improve the conventional PID controller performance with the introduction of the integral and derivation order $\lambda$ and $\mu$ respectively. However, in the computer science point of view, since additional parameters are added to the FO-PID controller, the process to obtain the controller parameters become more complex and simultaneously increase the computational time.

\section{OVERVIEW OF THE SLIDING MODE CONTROL APPROACH}

The pioneering work of variable structure with sliding mode notion designed in continuous time has been established in the early 1960's in Russia. The concept is not disseminated over a period of time when a book is published by Itkis (1976) [35], and a journal article written by Utkin (1977) [36]. After that, an insightful view regarding the introduction and the growth of the SMC control strategy has been carried out in [37]. Thereafter, a number of studies regarding the SMC have been proposed to deal with the uncertain and the nonlinear in the system. The design of the SMC is unique since its performance does not directly depend on the tracking state, while depending on the design of the sliding surface. The concept of the SMC technique is to force the control signal moving toward the sliding surface and force the control signal to stay on that surface one the control signal is reached [38]. Generally, the design of SMC has a structure as demonstrated in Fig. 3.

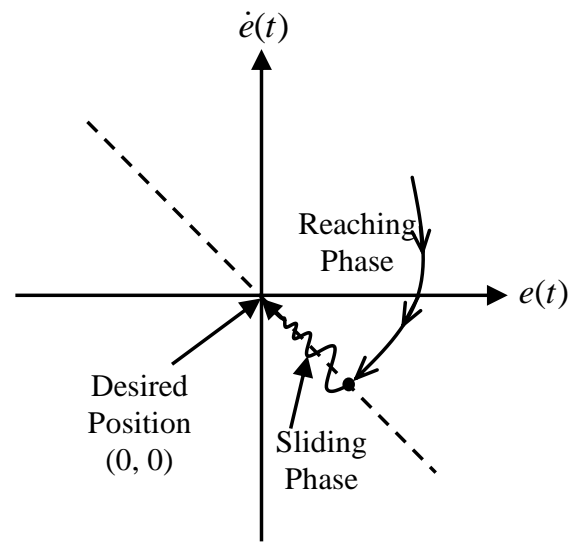

\section{Fig. 3. The fundamental idea and structure of the sliding} mode controller

Commonly, the general equation of the sliding surface, $s(t)$ in SMC can be obtained by referring to the system order, $n$ as presented in the following equation.

$s(t)=\left(\lambda+\frac{d}{d t}\right)^{n-1} e(t)$

Referring to the third order EHA system, the $s(t)$ of the conventional SMC, which is proportional to the error, $e$ and the control gain, $\lambda$ can be obtained as

$s(t)=\ddot{e}(t)+2 \lambda \dot{e}(t)+\lambda^{2} e(t)$

The error produced in a closed-loop environment can be

acquired in (5) by subtracting the output of the desired tracking with the actual tracking.

$e(t)=x_{r}(t)-x_{p}(t)$

The third order linearized EHA system will generate the error with the third derivative as expressed in (6).

$\dddot{e}(t)=\dddot{x}_{r}(t)-\dddot{x}_{p}(t)$

When the $s(t) \neq 0$, switching control, $u_{s w}$ will take place to leads the tracking error from the phase of reaching to sliding. While the $s(t)=0$, equivalent control, $u_{e q}$ will response to leads the tracking error on $s(t)=0$ to the desired point. Thus, the SMC generally expressed as

$u_{s m c}(t)=u_{e q}(t)+u_{s w}(t)$

The $u_{e q}$ of the SMC will be acquired through the first derivative of the $s(t)$ as

$\dot{s}(t)=\dddot{e}(t)+2 \lambda \ddot{e}(t)+\lambda^{2} \dot{e}(t)$

Some parameters exist in the EHA may impossible to be gathered and modelled. The simplified EHA model will be employed in the designed controller, where the EHA system will be represented through the perturbed linear model with third order, which has included the disturbances and uncertainties characters as indicated in the following equation.

$$
\begin{gathered}
\dddot{x}_{p}(t)=-\left(A_{n}+\Delta A\right) \ddot{x}_{p}(t)-\left(B_{n}+\Delta B\right) \dot{x}_{p}(t)+\cdots \\
\cdots+\left(C_{n}+\Delta C\right) u(t)+d(t)
\end{gathered}
$$

where $d(t)$ is composed of the nonlinear leakage and friction, and the external load disturbance. The nominal system parameters are represented in $A_{n}, B_{n}$, and $C_{n}$, while the uncertainties existed in the unmodeled dynamics are represented by the bounded uncertainties $\Delta A, \Delta B$, and $\Delta C$. Then, the third-order EHA system will be organized as

$\dddot{x}_{p}(t)=-A_{n} \ddot{x}_{p}(t)-B_{n} \dot{x}_{p}(t)+C_{n} u(t)+L(t)$

where $L(t)$ is the lumped uncertainties that can be expressed as: 
$L(t)= \pm \Delta A \ddot{x}_{p}(t) \pm \Delta B \dot{x}_{p}(t) \pm \Delta C u(t)+d(t)$

By assume $L$ is neglected and substituting (6) into (8), the $u_{e q}$ of the SMC will be indicated as

$u_{e q}(t)=\frac{1}{C}\left(\dddot{x}_{r}+A_{n} \ddot{x}_{p}+B_{n} \dot{x}_{p}+2 \lambda \ddot{e}(t)+\lambda^{2} \dot{e}(t)\right)$

The switching control of the SMC can be acquired by employing the signum function, $\operatorname{sign}(s)$ into the sliding surface as expressed in (13).

$u_{s w}(t)=k_{s} \operatorname{sign}(s)$

where the signum function has a boundary as expressed in (14), and $k_{s}$ is a positive constant value.

$$
\operatorname{sign}(s(t))= \begin{cases}1 & ; s(t)>0 \\ 0 & ; s(t)=0 \\ -1 & ; s(t)<0\end{cases}
$$

The Lyapunov theorem as adopted in [39-43] is used to analyse the stability of the controller when $s(t) \neq 0$ with the following function.

$V(t)=\frac{1}{2} s^{2}(t)$

The following reaching condition is required to be fulfilled to achieve the stable condition during the tracking from reaching to sliding phase.

$\dot{V}(t)=s(t) \dot{s}(t)<0$, for $s(t) \neq 0$

By replacing (6), (7) and (8) into (16), the following function will be obtained.

$$
\begin{aligned}
s(t) \dot{s}(t)= & s\left[\dddot{x}(t)_{r}+A_{n} \ddot{x}_{p}(t)+B_{n} \dot{x}_{p}(t)-C_{n}\left(u_{e q}(t)\right.\right. \\
& \left.\left.\cdots+u_{s w}(t)\right)+2 \lambda \ddot{e}(t)+\lambda^{2} \dot{e}(t)\right]
\end{aligned}
$$

The discontinuous function in (13) might leads to the chattering effect, which can be minimized by replacing the hyperbolic tangent function as introduced in [40-42].

$u_{s w}(t)=k_{s} \tanh \left(\frac{s}{\phi}\right)$

\section{Performance Analysis \& RESUltS}

It is well-known that the real-time applications can be performed better by the assistant of the controller. In addition, to overcoming the existing drawback of the system, the designed controller might reduce the actual required elements, for example, the voltage or power that generates torque to actuate the load or the application. Apart from reducing the actual effort, the powerful controller can perform surprisingly, even with the changes in the system parameters along the operation.

Therefore, in this paper, three different controllers have been designed to control the EHA system. Each controller has their own strength and weakness and performed differently with the error generated as illustrated in Fig. 4.

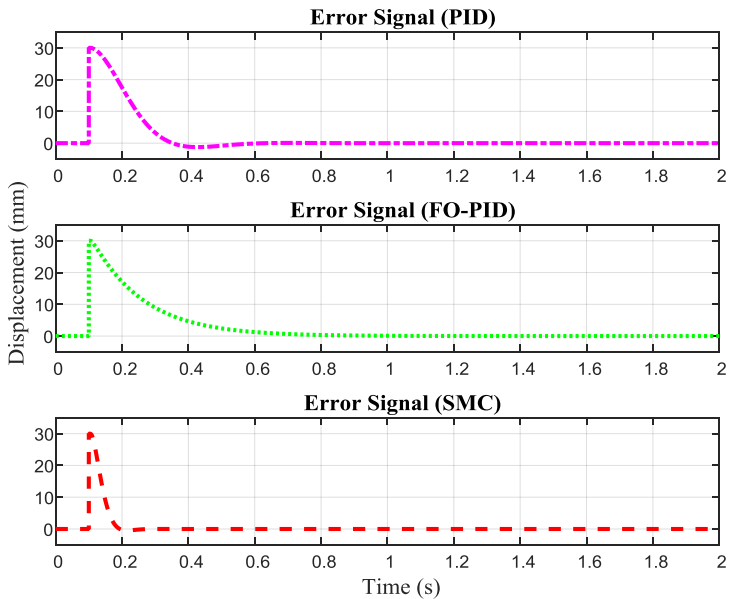

\section{Fig. 4. Performance and error generated by each controller}

To analyze the controller's performance in the field of control, the root means square error (RMSE), transient response and steady-state error analyses are the commonly used methods and very useful in generating numerical data for the comparison purpose. By referring to the responses as depicted in Fig. 5, the numerical data of each controller has been summarized and tabulated in Table I.

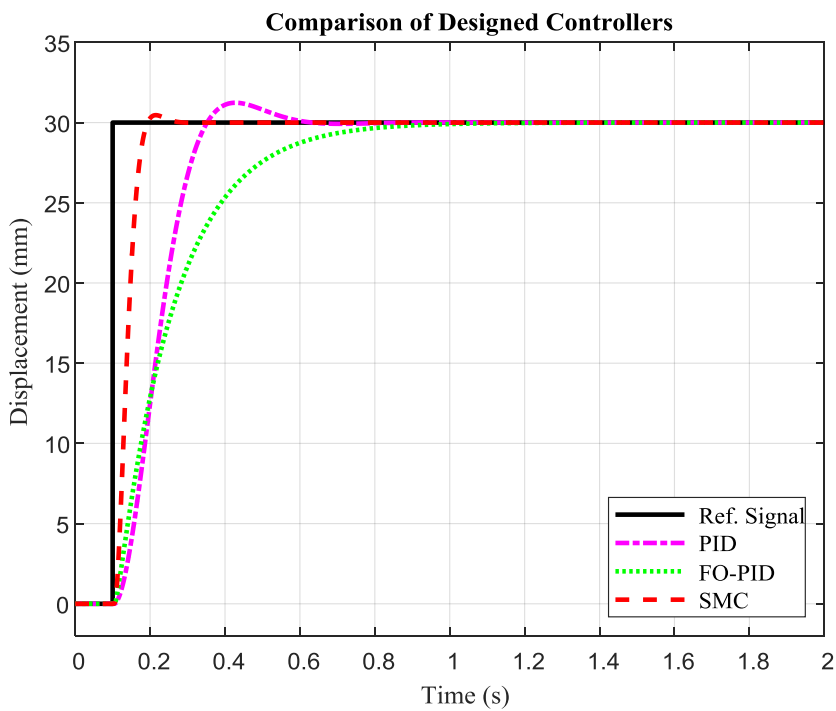

Fig. 5. Performance comparison of each controller 
Table I. Numerical analysis of each controller based on transient and RMSE analysis simple and much easier to understand is usually used. Depends on the required outcome, if the high precision result is required, the PID controller might insufficiently achieve this objective. This paper intends to assess the performance of the common use PID controller, the improved PID controller named fractional order PID controller, and also the SMC controller applied to the EHA system. It is observed from the 17.674 result, although the FO-PID controller is able to perform 8 better than the conventional PID controller, it is still unable to 17.290 surpass the performance of the SMC. Apart from using the 0 PSO computational tuning method, the performance of these 13.950 controllers might be enhanced through different 4 computational tuning methods. Therefore, further investigation regarding the computational tuning algorithm which can be applied in the practical system will be carried out. Whether to improve the performance of the particular system, or to enhance the capability of the controller that is able to apply to numerous applications.

\section{ACKNOWLEDGMENT}

The support of Universiti Teknikal Malaysia Melaka (UTeM), Universiti Teknologi Malaysia (UTM) and Ministry of Education (MOE) are greatly acknowledged. The research was funded by Short Term Grant No. PJP/2017/FKE/HI11/S01534, Fundamental Research Grant Scheme (FRGS) Grant No FRGS/1/2017/TK04/FKE-CERIA/F00333, and UTeM Zamalah Scheme. the former condition which produced the fastest rise time wir 0.0532 seconds, fastest settling time with 0.1852 seconds, lowest steady-state error and RMSE compared to PID and FO-PID controllers. The performance produced by the SMC is usually required in various applications, especially the application where high precision is required. Instead of using the conventional tuning techniques, for example, the try and error, and the Ziegler-Nichols tuning technique, the PSO computational tuning technique has been used to obtain the controller's parameter as listed in Table II, which is very time saving and convenient.

Table II. Parameters achieved through PSO tuning method

\begin{tabular}{cccccc}
\hline \multirow{2}{*}{ Controller } & \multicolumn{5}{c}{ Parameter } \\
\cline { 2 - 6 } & $\boldsymbol{K}_{\boldsymbol{p}}$ & $\boldsymbol{K}_{\boldsymbol{i}}$ & $\boldsymbol{K}_{\boldsymbol{d}}$ & $\boldsymbol{\lambda}$ & $\boldsymbol{\delta}$ \\
\hline \multirow{2}{*}{ PID } & $\begin{array}{c}10.091 \\
0\end{array}$ & 0.0013 & $\begin{array}{c}-4.698 \\
5\end{array}$ & 1 & 1 \\
\multirow{2}{*}{ FO-PID } & $\begin{array}{c}34.899 \\
1\end{array}$ & 0.7052 & 8.5401 & 2.0296 & 8.1205 \\
\hline \multirow{2}{*}{ SMC } & \multicolumn{3}{c}{$\boldsymbol{\lambda}$} & \multicolumn{3}{c}{$\boldsymbol{\theta}$} \\
\cline { 2 - 6 } & \multicolumn{3}{c}{51.6241} & 358.7009 \\
\hline
\end{tabular}

\section{CONCLUSION}

Complex controller design usually requires professional that possess expertise in the field which usually produces satisfactory outcome, especially dealing with the system that is complex with uncertainties such as EHA system. When it's come to the industrial field, the PID controller, which is

\section{REFERENCES}

1. L. Love, E. Lanke, and P. Alles, "Estimating the Impact (Energy, Emissions and Economics) of the US Fluid Power Industry," Oak Ridge Natl. Lab. (ORNL), Oak Ridge, TN, pp. $1-27,2012$.

2. M. Jelali and A. Kroll, Hydraulic Servo-systems: Modelling, Identification and Control. Springer - Verlag London Limited, 2003.

3. C.-A. Bojan-Dragos, R.-E. Precup, M. L. Tomescu, S. Preitl, O.-M. Tanasoiu, and S. Hergane, "Proportional-Integral-Derivative Gain-Scheduling Control of a Magnetic Levitation System," Int. J. Comput. Commun. Control, vol. 12, no. 5, pp. 599-611, 2017.

4. I. Podlubny, "Fractional-Order Systems and PI $\lambda$ D $\mu$-controllers," IEEE Trans. Automat. Contr., vol. 44, no. 1, pp. 208-214, 1999.

5. D. Valerio and J. S. da Costa, "Tuning of Fractional PID Controllers with Ziegler-Nichols-Type Rules," Signal Processing, vol. 86, no. 10, pp. 2771-2784, 2006.

6. D. Maiti, A. Acharya, M. Chakraborty, A. Konar, and R. Janarthanan, "Tuning PID and PI $\lambda D \delta$ Controllers using the Integral Time Absolute Error Criterion," in 2008 4th International Conference on Information and Automation for Sustainability, pp. 1-6.

7. J. Zhao, J. Wang, and S. Wang, "Fractional Order Control to the Electro-Hydraulic System in Insulator Fatigue Test Device," Mechatronics, vol. 23, no. 7, pp. 828-839, 2013. 
8. T. Sangpet and S. Kuntanapreeda, "Force Control of an Electrohydraulic Actuator using a Fractional-Order Controller," Asian J. Control, vol. 15, no. 3, pp. 764-772, 2013.

9. Z. Chen, X. Yuan, B. Ji, P. Wang, and H. Tian, "Design of a Fractional Order PID Controller for Hydraulic Turbine Regulating System Using Chaotic Non-Dominated Sorting Genetic Algorithm II," Energy Convers. Manag., vol. 84, pp. 390-404, 2014.

10. R. Wang, C. Tan, J. Xu, Z. Wang, J. Jin, and Y. Man, "Pressure Control for a Hydraulic Cylinder Based on a Self-Tuning PID Controller Optimized by a Hybrid Optimization Algorithm," Algorithms, vol. 10, no. 1, pp. 1-13, 2017.

11. C. C. Soon, R. Ghazali, H. I. Jaafar, S. Y. S. Hussien, S. M. Rozali, and M. Z. A. Rashid, "Position Tracking Optimization for an Electro-hydraulic Actuator System," J. Telecommun. Electron. Comput. Eng., vol. 8, no. 7, pp. 1-6, 2016.

12. Y. Ye, C.-B. Yin, Y. Gong, and J. Zhou, "Position Control of Nonlinear Hydraulic System Using an Improved PSO Based PID Controller," Mech. Syst. Signal Process., vol. 83, pp. 241-259, 2017.

13. C. C. Soon, R. Ghazali, H. I. Jaafar, and S. Y. S. Hussien, "PID Controller Tuning Optimization using Gradient Descent Technique for an Electro-hydraulic Servo System,” J. Teknol. Sci. Eng., vol. 77, no. 21, pp. 33-39, 2015.

14. T. Samakwong and W. Assawinchaichote, "PID Controller Design for Electro-hydraulic Servo Valve System with Genetic Algorithm," Procedia Comput. Sci., vol. 86, no. March, pp. 91-94, 2016.

15. C. C. Soon, R. Ghazali, H. I. Jaafar, S. Y. S. Hussien, Y. M. Sam, and M. F. Rahmat, "Controller Parameter Optimization for an Electro-hydraulic Actuator System based on Particle Swarm Optimization," J. Teknol., vol. 78, no. 6-13, pp. 101-108, 2016.

16. L. Fei, J. Wang, L. Zhang, Y. Ge, and K. Li, "Fractional-Order PID Control of Hydraulic Thrust System for Tunneling Boring Machine," in 2013 International Conference on Intelligent Robotics and Applications, pp. 470-480.

17. D. Bai and C. Wang, "Parameter Calibration and Simulation of Fractional PID Controller for Hydraulic Servo System," in 2016 Chinese Control and Decision Conference, pp. 1704-1708.

18. J. Liu, S. Vazquez, L. Wu, A. Marquez, H. Gao, and L. G. Franquelo, "Extended State Observer-Based Sliding-Mode Control for Three-Phase Power Converters," IEEE Trans. Ind. Electron., vol. 64, no. 1, pp. 22-31, 2017.

19. R. Cui, L. Chen, C. Yang, and M. Chen, "Extended State Observer-Based Integral Sliding Mode Control for an Underwater Robot with Unknown Disturbances and Uncertain Nonlinearities," IEEE Trans. Ind. Electron., vol. 64, no. 8, pp. 6785-6795, 2017.

20. J. J. More, P. F. Puleston, C. Kunusch, and M. A. Fantova, "Development and Implementation of a Supervisor Strategy and Sliding Mode Control Setup for Fuel-Cell-Based Hybrid Generation Systems," IEEE Trans. Energy Convers., vol. 30, no. 1, pp. 218-225, 2015.

21. J. J. Rath, M. Defoort, H. R. Karimi, and K. C. Veluvolu, "Output Feedback Active Suspension Control with Higher Order Terminal Sliding Mode," IEEE Trans. Ind. Electron., vol. 64, no. 2, pp. 1392-1403, 2017.

22. C. C. Soon, R. Ghazali, H. I. Jaafar, S. M. Rozali, Y. M. Sam, and M. F. Rahmat, "The Effects of Pressure Variation in Sliding Mode Controller with Optimized PID Sliding Surface," in 2017 Asian Simulation Conference, pp. 104-115.

23. Y. Wang, G. Luo, L. Gu, and X. Li, "Fractional-Order Nonsingular Terminal Sliding Mode Control of Hydraulic Manipulators Using Time Delay Estimation,” J. Vib. Control, vol. 22, no. 19, pp. 3998-4011, 2016.

24. C. C. Soon, R. Ghazali, H. I. Jaafar, S. Y. S. Hussien, S. M. Rozali, and M. Z. A. Rashid, "Optimization of Sliding Mode
Control using Particle Swarm Algorithm for an Electro-Hydraulic Actuator System," J. Telecommun. Electron. Comput. Eng., vol. 8, no. 7, pp. 71-76, 2016.

25. S. M. Rozali, N. S. Farhana, M. N. Kamarudin, A. F. Z. Abidin, M. F. Rahmat, A. R. Husain, and C. C. Soon, "Robust Control Design of Nonlinear System via Backstepping-PSO with Sliding Mode Techniques," in 2017 Asian Simulation Conference, pp. 27-37.

26. C. C. Soon, R. Ghazali, H. I. Jaafar, and S. Y. S. Hussien, "Sliding Mode Controller Design with Optimized PID Sliding Surface Using Particle Swarm Algorithm," Procedia Comput. Sci., vol. 105, no. Iris 2016, pp. 235-239, 2017.

27. S. M. Othman, M. F. Rahmat, S. M. Rozali, and Z. Has, "Optimization of Modified Sliding Mode Controller for an Electro-hydraulic Actuator system with Mismatched Disturbance,” Int. J. Electr. Comput. Eng., vol. 8, no. 4, 2018.

28. M. Mahmoodabadi, M. Taherkhorsandi, M. Talebipour, and K. Castillo-Villar, "Adaptive Robust PID Control Subject to Supervisory Decoupled Sliding Mode Control Based Upon Genetic Algorithm Optimization," Trans. Inst. Meas. Control, vol. 37, no. 4, pp. 505-514, 2015.

29. C. C. Soon, R. Ghazali, H. I. Jaafar, S. Y. S. Hussien, Y. M. Sam, and M. F. Rahmat, "The Effects of Parameter Variation in Open-Loop and Closed-Loop Control Scheme for an Electro-hydraulic Actuator System," Int. J. Control Autom., vol. 9, no. 11, pp. 283-294, 2016.

30. C. C. Soon, R. Ghazali, H. I. Jaafar, and S. Y. S. Hussein, S. M. Rozali, "Robustness Analysis of an Optimized Controller via Particle Swarm Algorithm,” Adv. Sci. Lett., vol. 23, no. 11, pp. 11187-11191, 2017.

31. M. Zamani, M. Karimi-Ghartemani, N. Sadati, and M. Parniani, "Design of a Fractional Order PID Controller for an AVR using Particle Swarm Optimization," Control Eng. Pract., vol. 17, no. 12, pp. 1380-1387, 2009.

32. I. Podlubny, "Fractional-Order Systems and Fractional-Order Controllers," Inst. Exp. Physics, Slovak Acad. Sci. Kosice, vol. 12, no. 3, pp. 1-18, 1994.

33. M. Dulau, A. Gligor, and T.-M. Dulau, "Fractional Order Controllers Versus Integer Order Controllers,” Procedia Eng., vol. 181, pp. 538-545, 2017.

34. Y. Chen, I. Petras, and D. Xue, "Fractional Order Control - A Tutorial," in 2009 American Control Conference, pp. 1397-1411.

35. U. Itkis, Control Systems of Variable Structure. New York: Halsted Press - John Wiley Sons, Inc., 1976.

36. V. Utkin, "Variable Structure Systems with Sliding Modes," IEEE Trans. Automat. Contr., vol. 22, no. 2, pp. 212-222, 1977.

37. R. A. DeCarlo, S. H. Zak, and G. P. Matthews, "Variable Structure Control of Nonlinear Multivariable Systems: A Tutorial," Proc. IEEE, vol. 76, no. 3, pp. 212-232, 1988.

38. C. Edwards and S. K. Spurgeon, Sliding Mode Control: Theory and Applications. Taylor and Francis, 1998.

39. Chen, H. M., Renn, J. C., \& Su, J. P. (2005). Sliding mode control with varying boundary layers for an electro-hydraulic position servo system. International Journal of Advanced Manufacturing Technology, 26(1-2), 117-123. http://doi.org/10.1007/s00170-004-2145-0

40. Eker, I. (2006). Sliding Mode Control with PID Sliding Surface and Experimental Application to an Electromechanical Plant. ISA Transactions, 45(1), 109-118.

41. Eker, I. (2010). Second-order Sliding Mode Control with Experimental Application. ISA Transactions, 49(3), 394-405.

Published By:

Blue Eyes Intelligence Engineering \& Sciences Publication 
42. Eker, I., \& Akinal, S. A. (2008). Sliding mode control with integral augmented sliding surface: design and experimental application to an electromechanical system. Electrical Engineering, 90(3), 189-197. http://doi.org/10.1007/s00202-007-0073-3

43. Mihajlov, M., Nikolic, V., \& Antic, D. (2002). Position Control of an Electro-Hydraulic Servo System using Sliding Mode Control Enhanced by Fuzzy PI Controller. Facta Universitatis-Series: Mechanical Engineering, 1(9), $1217-1230$. 